\title{
DOS LEYES DE LA EVOLUCIÓN PENAL1
}

\author{
Emile Durkheim*
}

\begin{abstract}
O texto discute as mudanças da punição ao longo da história das sociedades. Analisa o abrandamento do castigo físico e a ascensão da prisão como lócus central da punição no mundo moderno. Relaciona estes processos com a diferenciação social, caráter do poder e mudança na concepção dos delitos. Aponta a necessidade de criação de instituições penais que respondam melhor às novas aspirações da consciência moral.

PALAVRAS ChavE: evolução penal, castigo físico, prisão, consciência moral.
\end{abstract}

En el estado actual de las ciencias sociales, a menudo no se puede traducir en fórmulas inteligibles más que los aspectos generales de la vida colectiva. Sin duda, se llega sólo a aproximaciones a veces groseras, pero que no dejan de ser útiles ya que son una primera toma de espíritu sobre las cosas, y por esquemáticas que sean, son la condición previa y necesaria de precisiones ulteriores.

Es con esta reserva que vamos a buscar establecer y explicar dos leyes que parecen dominar la evolución del sistema represivo. Está bien claro que nos atendremos a las variaciones más generales, pero si logramos introducir un poco de orden en esta masa confusa de hechos, por imperfecta que sea, nuestra empresa no será inútil.

Las variaciones que ha sufrido el castigo a lo largo del curso de la historia son de dos tipos: unas cuantitativas, otras cualitativas. Las leyes que las gobiernan son necesariamente diferentes.

\footnotetext{
1 (Journal Sociologique PUF 1969). Publicado, originalmente en Année Sociologique. Volumen IV 1899-1900 Traducción. Mónica Escayola Lara Delito y Sociedad. Revista de Ciencias Sociales. N¹3, 1999, pp. 71-90
}

\section{LALEY DE LAS VARIACIONES CUANTITATIVAS}

Puede formularse del siguiente modo: "La intensidad del castigo es mayor en la medida que la sociedad pertenece a un tipo menos desarrollado y al grado en que el poder central tiene un carácter más absoluto".

Comencemos explicando el significado de estas expresiones. La primera no precisa definición. Es relativamente fácil reconocer cuándo un tipo social se halla más o menos desarrollado que otro: solamente tenemos que distinguir qué grado de simplicidad los compone y, si son de composición pareja, el grado de organización que manifiestan. Esta jerarquía de tipos sociales no implica, sin embargo, que el desarrollo de las sociedades forme una secuencia única y lineal. Por el contrario, es cierto que sería mejor representarla como un árbol, con muchas ramas que difieren en mayor o menor grado. Las sociedades se hallan situadas en diversas alturas de este árbol y a distancias variables del tronco común. ${ }^{2} \mathrm{Si}$ las tratamos de ${ }^{2}$ v. Regles de La méthode sociologique, cap. IV. 
este modo es posible hablar de la evolución general de las sociedades.

$\mathrm{El}$ segundo factor que distinguimos merece una discusión más profunda.

Llamamos al poder gubernamental "absoluto" cuando no hay otras funciones sociales similares para balancearlo y limitarlo efectivamente. En realidad la ausencia completa de toda limitación nunca se encuentra, se puede decir que es inconcebible. La tradición y las creencias religiosas sirven como freno aún sobre los más poderosos de los gobiernos. Por otra parte, siempre hay cierto número de órganos secundarios capaces, en ocasiones, afirmarse y de resistir. Las funciones subordinadas, que están sujetas a la función reguladora suprema, nunca pierden, sin embargo, toda su energía individual. Pero sucede que esta limitación de hecho no tiene nada jurídicamente obligatorio para el gobierno que la sufre, que aunque tenga cierta mesura en el ejercicio de sus prerrogativas, no lo hace por el derecho escrito o consuetudinario. En este caso, el gobierno ostenta un poder que se puede llamar absoluto. Sin duda, si el gobierno se deja llevar a excesos, las fuerzas sociales sobre las que avanza pueden unirse para reaccionar y contenerlo. Como anticipación a esta posible reacción dicho gobierno puede incluso ponerse límites por sí mismo. Pero esta contención, sea su propio hecho, o sea materialmente impuesta, es esencialmente contingente; no resulta del funcionamiento normal de las instituciones. Cuando se deben a la iniciativa gubernamental se presentan como una graciosa concesión, como un abandono voluntario de derechos legítimos. Cuando son el producto de la resistencia colectiva tienen un carácter francamente revolucionario.

Uno puede caracterizar al gobierno absoluto todavía de otra manera. La vida jurídica gravita toda entera sobre dos polos: Las relaciones que forman su trama son unilaterales o, por el contrario, bilaterales y recíprocas. Estos son, al menos, los dos tipos ideales alrededor de los que oscilan. Las primeras están constituidas exclusivamente por los derechos atribuidos a uno de los términos de la relación sobre el otro, sin que el segundo disfrute de derecho alguno correlativo a sus obligaciones. En las segundas, en cambio, el lazo jurídico resulta de una reciprocidad perfecta entre los derechos conferidos entre ambas partes. Los derechos reales, y más particularmente el derecho de propiedad, representan la forma más acabada de las relaciones del primer género: el propietario tiene derecho sobre su cosa, la que no tiene ninguno sobre él. El contrato, sobre todo el contrato justo, es decir, en el que hay una equivalencia perfecta en el valor social de las cosas o prestaciones intercambiadas, es el prototipo de las relaciones recíprocas. Ahora bien, cuanto mayor sea el grado en el que las relaciones entre el poder supremo y el resto de la sociedad sean de carácter unilateral, en otras palabras cuanto más se parezcan a aquéllas que unen a la persona con su posesión, más absoluto es el gobierno. Por el contrario, cuanto más bilateral sea la relación con otras funciones sociales, menos absoluto será el estado. De ese modo, el modelo más perfecto de soberanía absoluta es la patria potestas de los romanos tal cual fue definida en el viejo derecho civil, dado que el hijo está asimilado a una cosa.

Así, lo que hace al poder central más o menos absoluto es la ausencia más o menos radical de todo contrapeso permanente organizado con el objeto de moderarlo. Uno puede entonces prever que lo que da nacimiento a un poder de este tipo es la reunión más o menos completa de todas las funciones directivas de la sociedad en una misma mano. En efecto, por su importancia vital, no pueden concentrarse en una sola y misma persona, sin darle a ésta una preponderancia excepcional sobre el resto de la sociedad, y esta preponderancia constituye el absolutismo. Quien detenta tal autoridad está investido de una fuerza que lo libera de cualquier coacción colectiva y que, al menos en cierta medida, no dependa sino de sí mismo y de sus ganas, y pueda imponer su voluntad completamente. Esta hipercentralización da lugar a una fuerza social sui generis tan intensa que domina a todas las otras y las subordina. Esta preponderancia no se ejerce solamente de hecho sino también en derecho, porque quien tiene el privilegio está investido de tal prestigio que parece de naturaleza sobrehumana. 
No se concibe que pueda someterse a obligaciones regulares como el común de los hombres.

Tan breve e imperfecto como pudiera parecer este análisis, será sin embargo suficiente para evitarnos algunos errores frecuentes. Se ve, en efecto, que contrariamente a la confusión cometida por Spencer, el absolutismo gubernamental no varía según el número y la importancia de las funciones gubernamentales. Por numerosas que ellas sean, si no están concentradas en una sola mano, el gobierno no es absoluto. Es lo que ocurre hoy en nuestras grandes sociedades europeas y en particular en Francia. El campo de acción del Estado está mucho más extendido que bajo Luis XIV, pero los derechos que tiene sobre la sociedad no van sin deberes recíprocos; no se parecen al derecho de propiedad. Es que, en efecto, no sólo las funciones reguladoras supremas están repartidas entre órganos distintos y relativamente autónomos, aunque solidarios, sino que ellas no se ejercen sin la participación de otras funciones sociales. Así, aunque el Estado hace sentir su acción sobre mayor número de puntos, no deviene por ello más absoluto. Puede hacerlo, es cierto, pero para ello hacen falta otras circunstancias además de la mayor complejidad de atribuciones que le son otorgadas. Inversamente, la extensión mediocre de sus funciones no constituye un obstáculo para que el estado tome carácter de absoluto. En efecto, si ellas son poco numerosas y poco ricas en actividad, es la vida social misma, en su generalidad, pobre y languideciente; puesto que el desarrollo más o menos considerable del órgano regulador central no hace sino reflejar el desarrollo de la vida colectiva en general, así como las dimensiones del sistema nervioso, en el individuo, varían conforme la importancia de sus cambios orgánicos. Las funciones directrices de la sociedad sólo son rudimentarias cuando las demás funciones sociales lo son; y así la relación entre unas y otras resta igual. Por lo tanto, las primeras guardan toda su supremacía y es suficiente que sean absorbidas por un solo y único individuo para ponerlo fuera de sus pares, para elevarlo infinitamente sobre la sociedad. Nada es más simple que el gobierno de ciertos reinaditos bárbaros; nada es más absoluto. Esta reflexión nos conduce a otra que interesa más directamente a nuestro tema: es que el carácter más o menos absoluto del gobierno no es solidario de tal o cual tipo social. Si, en efecto, puede encontrarse indiferentemente donde la vida colectiva es extremadamente simple tanto como si es muy compleja, no es una característica exclusiva de las sociedades menos desarrolladas, como tampoco lo es de las otras. Es cierto, uno puede considerar que la concentración de los poderes gubernamentales siempre va de la mano con la concentración de la masa social, ya sea porque la primera es una consecuencia de la segunda o porque contribuya a formarla. Pero no es el caso. La sociedad romana, particularmente después de la caída de los reyes, estuvo completamente libre de absolutismo hasta el último siglo de la República. Los diferentes segmentos de las sociedades parciales (gentes) que la componían alcanzaron un altogrado de concentración y de fusión precisamente bajo la República. De hecho, en el resto, se observan formas de gobierno que merecen ser llamadas absolutas en los más diferentes tipos sociales, en Francia del siglo XVII y al final del Estado Romano, o en una multitud de monarquías bárbaras. Inversamente, un mismo pueblo, según las circunstancias, puede pasar de un gobierno absoluto a otro completamente diferente, sin embargo, una misma sociedad no puede cambiar de tipo en el curso de su evolución más de lo que un animal puede cambiar de especie durante su existencia individual. La Francia del siglo XVII y la del siglo XIX pertenecen al mismo tipo y sin embargo el órgano regulador supremo se transformó. Es imposible admitir que, de Napoleón I a Luis Felipe, la sociedad francesa haya pasado de una especie social a otra, para sufrir un cambio inverso de Luis Felipe a Napoleón III. Tales transmutaciones son incompatibles con la noción misma de especie. ${ }^{3}$

\footnotetext{
${ }^{3}$ He ahí porqué que nos parece poco científico clasificar las sociedades conforme a su estado de civilización, como lo han hecho Spencer y, aquí mismo, Steinmetz. Ya que, entonces, se está obligado a atribuir una sola y misma sociedad a una pluralidad de especies, siguiendo las formas políticas que ella ha sucesivamente revestido, o siguiendo los grados que ha progresivamente recorrido. ¿Qué diríamos de un zoólogo que fragmentara así un animal en distintas especies?. Una sociedad es
} 
Esta forma específica de la organización política no depende de la constitución básica de la sociedad sino de circunstancias particulares, transitorias y contingentes. He ahí por qué esos dos factores de la evolución penal - la naturaleza del tipo social y la del tipo gubernamental - deben ser cuidadosamente distinguidas. Es que, siendo independientes, actúan independientemente una de la otra y a veces, incluso, en sentido opuesto. Por ejemplo, ocurre que al pasar de una especie inferior a otras más elevadas, no se vea disminuir las penas como podría esperarse, porque, al mismo tiempo, la organización gubernamental neutraliza los efectos de la organización social. El proceso es, pues, muy complejo.

Explicada la fórmula de la ley, debemos ahora demostrar que se aplica a los hechos. Como no puede ser cuestión de pasar revista a todos los pueblos, elegiremos aquellos que han llegado a un cierto grado de desarrollo y que son conocidos con cierta determinación. En cuanto al resto, como lo hemos intentado mostrar en otros trabajos, lo esencial de una demostración sociológica no es abrumar con hechos, sino constituir series de variaciones regulares "cuyos términos se vinculen unos a otros por una graduación tan continua como posible, y que sean suficientemente extensos". ${ }^{4}$

En un gran número de sociedades ancianas, la muerte pura y simple no constituía la pena suprema; estaba agravada, para los crímenes reputados más atroces, por suplicios adicionales que tenían el objeto de tornarla más espantosa. Es así que entre los Egipcios, además de la horca y el degüello, encontramos la hoguera, el suplicio de las cenizas, la crucifixión. En la pena de fuego, el verdugo comienza por practicar, con juncos puntiagudos, varias incisiones en las manos del

por tanto, más aún que un organismo, una personalidad definida, idéntica a sí misma, en ciertos aspectos, de un extremo al otro de su existencia; en consecuencia, una

clasificación que desconozca esta unidad fundamental desfigura gravemente la realidad. Se pueden clasificar los estados sociales, no las sociedades; y estos estados sociales quedan en el aire, así desprendidos del sustrato permanente que los vincula unos a otros. Es entonces el análisis de ese sustrato, y no de la vida cambiante que él sostiene, el que sólo puede proveer las bases de una clasificación racional.

${ }^{4}$ Regles... p.163. culpable, y sólo después se lo acuesta en un lecho de espinas y se lo quema vivo. El suplicio de las cenizas consistía en ahogar al condenado en un montículo de cenizas. "Es probable, dice Thonissen, que los jueces tuvieran el hábito de infligir a los culpables todos los sufrimientos accesorios que creyeran requeridos por la naturaleza del crimen o las exigencias de la opinión pública". ${ }^{5}$ Los pueblos de Asia parecen haber llevado aún más lejos la crueldad. "Los Asirios arrojaban los culpables a las bestias feroces o dentro de una hoguera ardiente; se los quemaba a fuego lento dentro de una cuba de bronce; les reventaban los ojos. El estrangulamiento y la decapitación eran consideradas medidas insuficientes!. Los distintos pueblos de Siria lapidaban a los criminales, los atravesaban con flechas, los colgaban, los crucificaban, les quemaban las costillas y las entrañas con antorchas, los descuartizaban, los precipitaban por las rocas..., los hacían aplastar bajo las patas de animales, etc.” 6 El propio código de Manú distingue entre la muerte simple, que consistía en el degüello, y la muerte exasperada o calificada. Esta última es de siete especies: el palo, el fuego, el aplastamiento bajo las patas de un elefante, el ahogo, el aceite hirviente echado en las orejas y la boca, ser desgarrado por perros en una plaza pública, ser cortado en pedazos con navajas.

Entre estos mismos pueblos, la muerte simple era abundante. Es imposible hacer la enumeración de todos los casos que la imponían. Un hecho demuestra claramente cuan numerosas eran las condenas a muerte: de acuerdo a un relato de Diodoro, hubo un rey de Egipto, que al enviar a todos los condenados a morir al desierto, causó la fundación de una nueva ciudad; y otro, al emplearlos en trabajos públicos, consiguió construir numeroso diques y cavar canales. ${ }^{7}$

Por debajo de la pena de muerte se encontraban las mutilaciones expresivas. Así, en Egipto, a los falsos escribas, que alteraban las es-

${ }^{5}$ Etudes sur l'histoire du droit criminel des peuples anciens, I, p. 142

${ }^{6}$ Ibid., p.69.

${ }^{7}$ Cap. I, p. 60 y 65. 
crituras públicas, se les amputaban ambas manos; la violación de una mujer libre era castigada con la ablación de los genitales; se arrancaba la lengua del espía, etc. ${ }^{8}$ Del mismo modo, según las leyes de Manú, se corta la lengua al hombre

de la última casta que insulta gravemente a los Dwidjas; se marca sobre la cadera al Soudra que tenga la audacia de sentarse al lado de un Brahman, ${ }^{9}$ etc. Además de estas mutilaciones características, toda clase de castigos corporales eran usados en uno y otro pueblo. La mayor parte de las veces, las penas de este tipo eran arbitrariamente fijadas por el juez.

El pueblo hebreo no pertenecía, por cierto, a un tipo superior a los precedentes; en efecto, la concentración de la masa social no se produjo sino hasta una época relativamente tardía, bajo los reyes. Hasta entonces no había un Estado israelita, sino una mera yuxtaposición de tribus o clanes más o menos autónomos, y que no se coalicionaban más que momentáneamente para enfrentar peligros comunes. Sin embargo, la ley mosaica es mucho menos severa que la de Manu o los libros sagrados de Egipto. La pena capital ya no está rodeada de refinamientos ni de crueldad. Para, incluso, que durante largo tiempo, sólo la lapidación era empleada; solamente en los textos rabínicos aparece la cuestión del fuego, la decapitación y el estrangulamiento. ${ }^{10}$ La mutilación, tan ampliamente practicada por otros pueblos de Oriente, figura sólo una vez en el Pentateuco. ${ }^{11}$ El talión, es cierto, podía traer aparejadas mutilaciones cuando el crimen era una herida, pero el culpable podía siempre evadir esa pena mediante una composición pecuniaria; la indemnización sólo estaba prohibida para el homicidio. ${ }^{12}$ En cuanto a las otras penas corporales, que se reducían a la flagelación, estaban previstas para gran número de delitos: ${ }^{13}$ pero el número máximo de latigazos era 40 , y en la práctica, a $39 .{ }^{14}$

\footnotetext{
${ }^{8}$ Thonissen, I, p. 160.

${ }^{9}$ Benzinger, Hebraeische Archaeologie, p. 292-203, p. 71 y $\$ 41$.

${ }^{10}$ V. Benzinger, op. cit., p. 333; Thonissen, op. cit., II, P. 28.

${ }^{11}$ Deut., XXV, 11-12.

12 Nombres, XXXV, 31.

${ }^{13}$ Así esta explicado en un pasaje del Deuteronomio XXV, 1-2.

${ }^{14}$ Joséphe, Ant., IV, p. 238, 248.
}

¿De dónde viene esta relativa dulzura? Es que entre el pueblo hebreo, jamás pudo establecerse un gobierno absoluto de manera duradera. Hemos visto que, durante mucho tiempo, faltó incluso organización política. Más tarde, es cierto, se constituyó una monarquía, pero el poder de los reyes fue muy limitado: "En Israel siempre fue muy vivo el sentimiento de que el rey estaba allí para su pueblo y no el pueblo para su rey; debía ayudar a Israel, y no servirse de él en su propio interés". ${ }^{15}$ Aunque haya ocurrido alguna vez que ciertas personalidades conquistaran, en virtud de su prestigio personal, una autoridad excepcional, el espíritu del pueblo se conservó profundamente democrático.

Sin embargo, se ha podido ver que la ley penal no dejaba de ser muy dura. Si pasamos de las sociedades precedentes al tipo de la ciudad, que es incontestablemente superior, constatamos una regresión aún mayor de la penalidad. En Atenas, aunque la pena de muerte algunas veces era reforzada, ello era sin embargo la gran excepción. ${ }^{16}$ Consistía, en principio, en la muerte por cicuta, por la espada, o el estrangulamiento. Las mutilaciones expresivas desaparecieron. Parecen también desaparecidos los castigos corporales, salvo para los esclavos, y, quizás, para las personas de baja condición. ${ }^{17}$ Pero Atenas misma, considerada en su apogeo, representa una forma relativamente arcaica de la ciudad. En efecto, la organización sobre la base de clanes (fratrias) sólo fue completamente borrada en Roma, donde, desde muy temprano, curias y gens (gentes) se convirtieron en recuerdos históricos, de los cuales los propios romanos apenas si conocían el significado. El sistema de penas era también mucho más severo en Atenas que en Roma. En principio, el derecho ateniense, a pesar de lo que dijimos, no ignoraba la muerte exasperada. Demóstenes ha hecho alusiones a los culpables clavados a la horca: ${ }^{18}$ Lysias cita los nombres de los asesinos,

\footnotetext{
${ }^{15}$ Benzinger, op. cit., p. 312.

${ }^{16}$ V. Hermann, griech. Antq., II (I) Abtheil., p. 124-125.

${ }^{17}$ Hermann, op. cit., p. 126-127.

${ }^{18}$ C. Midias, 105, Cf. “Platon”, Rep., II, 362.
} 
bandoleros y espías muertos en el palo; ${ }^{19}$ Antífona habla de una envenenadora muerta en el suplicio de la rueda..$^{20} \mathrm{~A}$ veces la muerte estaba precedida por la tortura. ${ }^{21}$ Más aún, los casos en que la pena de muerte se pronunciaba eran considerables: "La traición, la lesión al pueblo ateniense, el atentado contra las instituciones políticas, la alteración del derecho nacional, las mentiras proferidas en la tribuna de la asamblea del pueblo, el abuso de las funciones diplomáticas, la concusión, la impiedad, el sacrilegio, etc., reclamaban incesantemente la intervención del terrible ministro de los Once". ${ }^{22}$ En Roma, por el contrario, los crímenes capitales eran mucho menos numerosos y las leyes Porcias restringieron la aplicación del último suplicio durante toda la República. ${ }^{23}$ Además, salvo en circunstancias completamente extraordinarias, la muerte no estaba rodeada de tortura accesoria ni agravación alguna. La cruz se reservaba sólo a los esclavos. Por otra parte, los romanos se vanagloriaban de la dulzura relativa de su sistema represivo: Nulli gentium miliores placuisse pocuas, Tito Lívio ${ }^{24}$ y Cicerón dijeron: Vestram libertatem, non acerbilate suppliciorum infestam, sed lenitate legum munitam esse voluerunt. ${ }^{25}$

Pero cuando, con el Imperio, el poder gubernamental tendió a devenir absoluto, la ley penal se agravó. En primer lugar se multiplicaron los crímenes capitales. El adulterio, el incesto, todo tipo de atentado contra las costumbres, pero sobre todo la cantidad siempre creciente de delitos de lesa majestad se penaron con la muerte. Al mismo tiempo, se instituyeron penas más severas. La hoguera, que estaba destinada a los crímenes políticos excepcionales, se empleó contra los incendiarios, los sacrílegos, los magos, los parricidas y algunos autores de delitos de lesa

${ }^{19}$ C. Agoratos, 56, 67, 68 y "Demosthéne”, Discours sur l'Ambassade, parágrafo 137.

${ }^{20}$ Acusación de envenenamiento, p. 20

${ }^{21}$ C. Agoratos, 54 y "Plutarque”, Phocion, XXXIV.

${ }^{22}$ Thonissen, op. cit., p. 100.

${ }^{23}$ Walter, Histoire de la procedure civile et du droit criminel chez les Romains, tr.fr., parágrafo 821, y Rein, Criminalrecht der Romer, p. 55.

${ }^{24}$ Tite-Live, I, p. 28.

${ }^{25}$ Pro Rabirio perduellionis reo, p. 3. majestad; se estableció la condenación ad opus publicum, se aplicaron mutilaciones a ciertos criminales (por ejemplo, la castración en ciertos atentados contra las costumbres, la mano cortada para los falsificadores, etc.). Finalmente hizo su aparición la tortura; es del período del Imperio que la Edad Media la tomará luego prestada.

$\mathrm{Si}$, de la ciudad, pasamos a las sociedades cristianas, vemos evolucionar las penas conforme la misma ley.

Sería un error juzgar la ley penal, bajo el régimen feudal, de acuerdo a la reputación de atrocidad que se ha otorgado a la Edad Media. Cuando se examinan los hechos, se constata que era mucho más dulce que en los tipos sociales anteriores, al menos si se la considera en la fase correspondiente de su evolución, es decir, a su período de formación, y por así decirlo, de primera juventud; y es bajo esta condición solamente que la comparación pude tener valor demostrativo. Los crímenes capitales no eran muy numerosos. Según Beaumanoir, los únicos hechos verdaderamente inexpiables eran el asesinato, la traición, el homicidio, la violación. Las Reglas de San Luis agregan el rapto y el incendio. ${ }^{26}$ Estos eran los principales casos de alta justicia. Sin embargo, aunque el bandolerismo no estuviera así calificado, era también un crimen capital. También lo eran dos delitos considerados particularmente atentatorios contra los derechos del Señor: las fechorías en el mercado y los delitos de caminos cortados (inversamente, con violencia, los puestos de peaje). ${ }^{27}$ En cuanto a los crímenes religiosos, los únicos que eran reprimidos con el último suplicio eran la herejía y la impiedad o incredulidad. Los sacrílegos sólo recibían una multa, igual que los blasfemos. El Papa Clemente IV censuró a San Luis cuando éste decidió, en el primer ardor religioso de su juventud, que los blasfemos serían marcados en la frente y se les perforaría la lengua. Sólo más tarde desplegó la Iglesia una severidad implacable contra sus

\footnotetext{
${ }^{26}$ Etablissements du Saint Louis, liv. I y XI.

${ }^{27}$ V. Du Boys, Histoire du Droit criminel des peoples modernes, t. II, p. 231.
} 
enemigos. En cuanto a las penas mismas, no tenían nada de exagerado. Las únicas agravaciones de la muerte consistían en ser arrastrado sobre zarzas y ser quemado vivo. Las mutilaciones eran raras. Se sabe, por otra parte, cuan humano era el sistema represivo de la Iglesia. Las penas que empleaba eran preferentemente penitencias y mortificaciones. Rechazaba la mortificación pública, el collar de hierro, la picota, aunque penas parecidas no excedieran su competencia. Es cierto que cuando la Iglesia juzgaba necesaria una represión sangrienta, entregaba el culpable a la justicia secular. No obstante, es un hecho de gran importancia que el más alto poder moral del tiempo

testimoniara así su horror a esta clase de castigos. ${ }^{28}$

Esa fue, más o menos, la situación hasta el siglo XIV. A partir de ese momento, el poder real se estableció más sólidamente. A medida que se consolidaba, se ve a las penas reforzarse. Primero los crímenes de lesa majestad, que eran desconocidos en el feudalismo, hicieron su aparición, y la lista de ellos era larga. Los crímenes religiosos son calificados, ellos mismos, así. Resulta entonces que el sacrilegio se convierte en un crimen social. También lo son el simple comercio con infieles, y toda tentativa de "hacer creer y argüir cosas contrarias a la Santa Fe de Nuestro Señor". Al mismo tiempo se manifiesta un mayor rigor en la aplicación de las penas. Los culpables de crímenes capitales podían ser sometidos a la rueda (es entonces que aparece el suplicio de la rueda), quemados vivos, descuartizados, empalados, hervidos. En ciertos casos, los hijos del condenado compartían el suplicio. ${ }^{29}$

El apogeo de la monarquía absoluta marca

${ }^{28}$ Esta dulzura relativa de la penalidad se acentúo mucho más en las partes de la sociedad gobernadas democráticamente, a saber, en las comunas libres. " En las ciudades libres, dice Du Boys (II; P. 370), como en las comunas propiamente dichas, se encuentra una tendencia a cambiar las penas por multas y usar la vergüenza más que los suplicios o las penas coercitivas como medio de represión. Así, en Mont Chabrier, el que robaba dos pesos estaba obligado a una multa de cinco pesos", Koheler hizo la misma apreciación sobre las ciudades italianas. (Das Strafrecht der italiennischen statuten vom 12-16. Jahrhundert).

${ }^{29}$ V. Du Boys, op. cit., p. 234, 237 y sig. el apogeo de la represión. En el siglo XVII, las penas capitales en uso eran aún las que acabamos de enumerar. Además, una pena nueva, la de las galeras, fue constituida, pena tan terrible que los desgraciados condenados se cortaban una mano o un pie para evitarla. El hecho era tan frecuente que se lo castigó con pena de muerte en una declaración de 1677. En cuanto a las penas corporales, eran innombrables: había arrancamiento o perforación de la lengua, absición de los labios, desorejamiento, la marca con hierro caliente, fustigación con el bastón, látigo o vara, etc. En fin, no debemos olvidar que la tortura se empleaba a menudo no solo como medio del procedimiento, sino como pena. Al mismo tiempo, los crímenes capitales se multiplicaban porque los crímenes de lesa majestad eran más numerosos. ${ }^{30}$

Tal era entonces la ley penal, hasta mediados del siglo XVII. Fue entonces que tuvo lugar, en toda Europa, la protesta a la que Beccaria ataría su nombre. Sin dudas, el criminalista italiano no fue la causa inicial de la reacción que continuaría después sin interrupción. El movimiento había comenzado antes de él. Numerosas obras, hoy olvidadas, ya habían aparecido reclamando una reforma del sistema penal. Es sin embargo incontestable que el Tratado de los delitos y de las penas dio el golpe mortal a las viejas y odiosas rutinas del derecho criminal.

Una ordenanza de 1788 ya había introducido algunas reformas, no sin importancia; pero fue sobre todo con el Código penal de 1810 que las nuevas aspiraciones recibieron una gran satisfacción. Así, cuando apareció, fue recibido con admiración y sin reservas, no solo en Francia, sino en los principales países de Europa. Realizaba, sin duda, un importante progreso en el sentido de la moderación. Sin embargo, estaba todavía muy unido al pasado. Así, nuevas mejoras no tardaron en ser reclamadas. Había quejas porque la pena de muerte, si bien no era agravada como en el antiguo régimen, se aplicaba muy pródigamente. Se veía como inhumano que se conservaban, la marca el ${ }^{30}$ Du Boys, op. cit., p. 62-81. 
látigo, la mutilación de puño para los parricidas. Fue para responder a esas críticas que se hizo la revisión de 1832, que introdujo en nuestra organización penal una suavidad mayor, eliminando todas las mutilaciones, disminuyendo los crímenes capitales, dando, en fin, a los jueces el modo de moderar todas las penas gracias al sistema de circunstancias atenuantes. No es necesario demostrar que, después, el movimiento continuó en igual dirección, ya que hoy ya hay quejas de que el régimen que reciben los criminales es muy confortable.

\section{LEY DE LAS VARIACIEONES CUALITATIVAS}

La ley que acabamos de exponer se refiere exclusivamente al monto o cantidad del castigo. Ahora vamos a referirnos a sus modalidades cualitativas. Puede expresarse como sigue: El castigo que implica la privación de la libertad y solamente de eso por períodos de tiempo que varían con la gravedad del crimen, tiende crecientemente a volverse el tipo normal de sanción.

Las sociedades inferiores las ignoran casi por completo. Aún en las leyes de Manu, hay todo un versículo que pareciera ser respecto de las prisiones: "Que el rey, dice, coloque todas las prisiones sobre la vía pública, a fin de que los criminales, afligidos y odiosos, sean expuestos a las miradas de todos". ${ }^{31}$ Una prisión semejante tiene un carácter bien distinto de las nuestras, es más bien análogo a la picota. El condenado es retenido prisionero para poder ser expuesto y también porque la detención es la condición necesaria de los suplicios que se le imponen, pero no constituye la pena en sí misma. La pena consistía en la dura existencia de los detenidos. El silencio de la ley mosaica es aún más completo. En el Pentateuco no se menciona la prisión ni una vez. Más tarde, en las Crónicas, en el libro de Jeremías, hay algunos pasajes que hablan de prisión, de grilletes, de fosas húmedas; ${ }^{32}$ pero en

${ }^{31}$ IX, p. 288.

${ }^{32}$ Crónicas. , XVI, 10 y XVIII, 26-Jeremías. , XXVII, 15 y 16. todo caso se trata de arrestos preventivos, de lugares de detención donde se encerraba a los acusados, los sujetos sospechados, hasta que un se dictara un juzgamiento, y donde estaban sometidos a un régimen más o menos severo, según las circunstancias. Estas medidas administrativas, arbitrarias o no, no constituían penas definidas respecto de crímenes definidos. Es solamente en el libro de Esdras que, por primera vez, la prisión aparece como pena propiamente dicha. ${ }^{33}$ En el viejo derecho eslavo y germano las penas simplemente privativas de la libertad parecen igualmente ignoradas. Era igual en los viejos cantones suizos hasta el siglo XIX. ${ }^{34}$

En la ciudad, comenzaron a hacer su aparición. Contrariamente a lo que dice Schoemann, parece certero que en Atenas, $n$ ciertos casos, la prisión era infligida a título de pena especial. Demóstenes dijo formalmente que los tribunales tienen derecho a castigar con prisión u otra pena. ${ }^{35}$ Sócrates habla de detención perpetua como una de las penas que se le podrían aplicar. ${ }^{36}$ Platon, al esbozar en De Las Leyes (el plan de la ciudad ideal, propone reprimir con prisión un gran número de infracciones y se sabe que su utopía estaba más cerca de la realidad histórica de lo que a veces se supone. ${ }^{37}$ Sin embargo, todo el mundo reconoce que en Atenas esta pena se desarrolló poco. A menudo, en los discursos de los oradores, la prisión es presentada como una

manera de evitar la huida de los acusados, o como un medio cómodo para constreñir a ciertos deudores a pagar sus deudas, o bien como un suplemento de la pena. Cuando los jueces se limitaban a fijar una multa, tenían el derecho de agregarle una detención de cinco días, con grilletes en los pies en la prisión pública. ${ }^{38}$ En Roma, la situación no era diferente. "La prisión, dice Rein,

\footnotetext{
3 "Para todos los que observan la ley de tu dios y la ley del rey, que sin contención sea hecha justicia, y quese los condene, sea a la muerte, sea al exilio..., sea a la prisión" (Esdras, VII, 26).

${ }^{34}$ Post, Bausteine f. eine allgemeine Rechtsw., I p. 219.

${ }^{35}$ Discours contre Timocrate, páragrafo 151.

${ }^{36}$ Apologie, p.37, c.

${ }^{37}$ Leyes, VIII, p. 847; IX, p. 864, 880.

${ }^{38}$ Hermann, Griech. Antiq. Rechhtsalterlhuemer, p. 126.
} 
no era originariamente más que un sitio de detención preventiva. Más tarde se convirtió en una pena. Sin embargo se la aplicaba poco, salvo a los esclavos, los soldados y los actores" ${ }^{39}$

Fue solamente en las sociedades cristianas que tomó todo su desarrollo. La Iglesia, en efecto, tomó muy temprano la costumbre de ordenar contra ciertos criminales la detención temporaria o la vida en un monasterio. En principio sólo fue considerada un modo de vigilancia, pero pronto la encarcelación o la prisión propiamente dicha fue tratada como verdadera pena. El máximo era la detención perpetua y solitaria en una celda que se enmuraba, como símbolo de la irrevocabilidad de la sentencia. ${ }^{40}$

Es de allí que la práctica pasó al derecho laico. Sin embargo, como la prisión era usada al mismo tiempo como medida administrativa, su significado penal permaneció largo tiempo dudoso. Sólo en el siglo XVIII los criminalistas terminaron por reconocer a la prisión el carácter de pena en ciertos casos definidos, cuando era perpetua, cuando había sustituido por conmutación la pena de muerte, etc. En una palabra, todas las veces que estaba precedida de una instrucción judicial. ${ }^{41}$ Con el derecho penal de 1791, devino la base del sistema represivo, que fuera de la pena de muerte y del collar de acero, no tenía más que diversas formas de detención. A pesar de ello la simple encarcelación no se consideraba una pena suficiente; se le agregaban privaciones de otro orden (cinturones o cadenas que llevaban los condenados, privaciones alimentarias). El código penal de 1810 dejó de lado las agravaciones, salvo para los trabajos forzados. Las otras dos penas privativas de la libertad no diferían en nada salvo en la duración del tiempo en que el reo estaba encerrado. Después, los trabajos forzados perdieron gran parte de sus rasgos característicos y tendieron a ser una variedad de la detención. Al mismo tiempo la pena de muerte fue de aplicación cada vez más rara; desapareció completamente de

${ }^{39}$ Criminalrecht del Roemer, p. 914.

${ }^{40}$ Du Boys, op. cit. V, p. 88-89.

${ }^{41}$ Du Boys, VI, op. cit., p. 60. algunos códigos, de forma tal que la supresión de la libertad por un tiempo o de por vida se encuentra ocupando poco a poco todo el dominio de la penalidad.

\section{EXPLOCACIÓN DE LA SEGUNDA LEY}

Después de haber determinado el modo en que la pena ha variado en el tiempo, vamos a buscar las causas de estas variaciones constatadas, es decir, trataremos de explicar las dos leyes previamente establecidas. Vamos a empezar con la segunda.

Como ya hemos visto, la detención no aparece en la historia sólo más que como medida meramente preventiva, para asumir más tarde un carácter represivo y, finalmente, convertirse en el tipo mismo de la pena. Para dar cuenta de esta evolución, debemos descubrir qué dio nacimiento a la prisión en su primera forma y, después, qué determinó el cambio que sufrió subsecuentemente.

Es fácil entender por qué la prisión preventiva se halla ausente en las sociedades menos desarrolladas: no hay necesidad con la que se corresponda. La responsabilidad, de hecho, es colectiva. Cuando se comete un crimen, el castigo por la reparación no es debido simplemente por la parte culpable sino también, ya junto con ella, ya en su lugar si ella falta, por el clan del que forma parte. Más tarde, cuando el clan ha perdido su carácter familiar, es un círculo, incluso relativamente extendido, de allegados. En estas condiciones no hay razón para arrestar y mantener bajo vigilancia al autor presunto del acto ya que si, por una razón o por otra, él falta, deja quienes respondan por él. Por otra parte, la independencia moral y jurídica, reconocida a cada grupo familiar, se opone a que se les pueda pedir que entreguen a uno de sus miembros por una simple sospecha. Pero en la medida en que la sociedad se vuelve más concentrada y estos grupos elementales pierden su autonomía y se disuelven en la gran masa, la responsabilidad se vuelve un asunto individual. A partir de entonces es necesario tomar medidas para asegurar que la represión no sea 
eludida por la fuga del que debe esperarla, y como al mismo tiempo esas medidas ya no vulneran la moral establecida, la prisión aparece. Es así que la encontramos en Atenas, Roma, entre los Hebreos después del exilio. Pero es tan contraria a la vieja organización social que tropieza con resistencias que restringen estrechamente su uso, en todas partes en donde el poder del Estado tiene alguna limitación. Es así que en Atenas la detención preventiva no estaba autorizada salvo en casos particularmente graves. ${ }^{42}$ Aún el homicida podía quedar libre hasta el día de su condena. En Roma, el prevenido "no era retenido prisionero salvo en caso de delito flagrante y manifiesto, o cuando había confesado. Generalmente una caución era suficiente". ${ }^{43}$

Se debe evitar explicar estas restricciones aparentes al derecho de arresto preventiva por un sentimiento de dignidad personal o de individualismo precoz que nunca conoció la moral de la ciudad. Lo que limita el derecho del Estado no es el derecho del individuo, sino el del clan, o la familia, o de lo que de ella queda. No es una anticipación de nuestra moral moderna sino la supervivencia del pasado.

Sin embargo esta explicación es incompleta. Para dar cuenta de una institución no alcanza con establecer que al momento de su aparición respondía a un fin útil, ya que ser deseable no la hacía necesariamente posible. Hay que ver, además, como se constituyeron las condiciones necesarias a la realización de ese fin. Una necesidad, aún intensa, no puede crear ex nihilo los modos de satisfacerla; hay que buscar de dónde vienen. Sin duda, en el primer abordaje, parece muy simple que el día que la prisión resultó útil a las sociedades, los hombres la construyeron. Pero en realidad ella supone realizadas algunas condiciones sin las cuales sería imposible. Implicaba la existencia de establecimientos públicos, suficientemente espaciosos, ocupados militarmente, acomodados de manera de impedir el contacto con el exterior, etc. Tales arreglos no se improvisan en un instante; no existen huellas de ellos en las sociedades

${ }^{42}$ V. El artículo "Carcer” en el Diccionario de Saglio.

${ }^{43}$ Walter, op. cit., páragrafo 856. inferiores. La vida pública, muy pobre, muy intermitente, no necesita acomodamientos especiales para desarrollarse, salvo un lugar para las reuniones populares. Las casas se construían con fines exclusivamente privados; las de los jefes, donde los había permanentes, apenas si se distinguían de las demás; los templos mismos tuvieron una aparición tardía; en fin, las murallas no existían, sólo aparecieron con la ciudad. En esas condiciones, la idea de una cárcel no podía nacer.

Pero a medida que se extendió el horizonte social, que la vida colectiva, e lugar de dispersarse en torno de una multitud de pequeños hogares donde sólo podía ser mediocre, se concentró en un número más restringido de puntos, se convirtió en más intensa y continua. Como tomó importancia, las viviendas de quienes se ocupaban de ella se transformaron. Se extendieron, se organizaron a la vista de funciones más extendidas y permanentes que les incumbían. Cuanto más aumentaba la autoridad de quienes las habitaban, más se singularizaban y distinguían de las restantes habitaciones. Tomaron grandes espacios, se refugiaron tras muros más altos, fosas más profundas, de manera de marcar visiblemente la línea que separa a los detentadores del poder de la masa de sus subordinados. Allí las condiciones de la prisión estaban dadas. Lo que hace suponer que así nació es que, en su origen, a menudo aparece la cárcel a la sombra del palacio del rey, en las dependencias de los templos o lugares similares. Así, en Jerusalén, había tres prisiones en la época de las invasiones de los caldeos, una en la "alta puerta de Benjamín", ${ }^{44}$ y se dice que las puertas eran lugares fortificados; otra en el patio del palacio del rey ${ }^{45} \mathrm{y}$ la tercera en la casa de un funcionario real. ${ }^{46}$ En Roma las prisiones más antiguas están en la fortaleza real ${ }^{47}$ En la Edad Media, en los castillos de los señores, o en las murallas que rodeaban las ciudades. ${ }^{48}$

\footnotetext{
${ }^{44}$ Jérémie,XX,2.

${ }^{45}$ Ibid.,XXXII, 2.

${ }^{46}$ Ibid.,XXXVII, 15.

${ }^{47}$ V.Art.”Carcer”,op.cit.

${ }^{48}$ V. Schaffroth,Geschicht d.Bernischen Gafaengnisswesens. Stroobant, Notas sobre el sistema penal de las ciudades flamencas.
} 
Así, al mismo tiempo que el establecimiento de un lugar de detención era útil por la desaparición progresiva de la responsabilidad colectiva, los monumentos que se levantaban podían ser utilizados para este oficio. La prisión, es verdad, sólo era preventiva. Pero una vez que se constituyó bajo ese título, tomó rápidamente carácter represivo, al menos parcialmente. En efecto, todos los que estaban retenidos prisioneros eran sospechosos, eran las más de las veces sospechosos de crímenes graves. Así estaban sometidos a un régimen severo que ya era, en sí mismo, una pena. Todo lo que sabemos de esas prisiones primitivas, que aún no eran instituciones propiamente penitenciarias, nos las pintan con tristes colores. En Dahomey, la cárcel es un agujero en forma de pozo, donde los condenados se pudren en las inmundicias

y parásitos. ${ }^{49}$ En Judea, hemos visto que consistían en fosas bajas. En el México antiguo, estaba hecho de jaulas de madera a las que los prisioneros eran atados y apenas alimentados. ${ }^{50}$ En Atenas les ponían grilletes. ${ }^{51}$ En Suiza, para hacer la evasión más difícil, se ponía a los presos un collar de hierro. ${ }^{52}$ En Japón, las prisiones son llamadas infiernos. ${ }^{53}$ Es natural que el tiempo pasado en tales lugares se considerara muy temprano como un castigo. Se reprimían también los pequeños delitos, sobre todo los cometidos por la pobre gente, las personae humiles como decían en Roma. Era una pena correccional de la que los jueces disponían más o menos arbitrariamente.

En cuanto a la fortuna jurídica de esta nueva forma de castigo en el momento de su aparición, es suficiente para dar cuenta de ella combinar las consideraciones precedentes con la ley relativa al progresivo debilitamiento de las sanciones penales. Su debilitamiento ocurre, en efecto, desde arriba hacia abajo de la escala penal. En general son las formas más duras de castigo las que se ven

${ }^{49}$ Abbé Laffitte,_Le Dahomé,Tours, 1873, p. 81.

${ }^{50}$ Bancroft, The native races of the Pacific States..., II, p.453.

${ }^{51}$ V. Thonissen, op. cit., p. 118.

${ }^{52}$ Schaffroth, Geschicht d.Bernischen Gafaengnisswesens.

${ }^{53}$ V. Letourneau, Evolution juridique, p.199. afectadas primero por este movimiento de retroceso, es decir, las que primero resultan suavizadas y luego desaparecen. Son las agravaciones del castigo capital los primeros que se debilitan, hasta que llega el momento en que son completamente suprimidos. Los casos en los que el castigo capital se aplica se vuelven más y más restringidos. El castigo por mutilación sigue la misma ley. Como consecuencia de esto, los castigos menores se vuelven más importantes, ya que deben llenar los vacíos que deja este proceso de regresión. En la medida en que las formas arcaicas de represión desaparecen del campo del sistema penal, las nuevas formas invaden los espacios vacíos que se abren frente a ellas. Ahora, las diversas formas de prisión comprenden las últimas formas de castigo que emergen.

En su origen ocupaban un lugar al final de la escala penal, ya que al principio no eran, hablando con propiedad, ni siquiera un tipo de castigo: simplemente constituían la condición para el castigo verdadero y por mucho tiempo mantuvieron un carácter mezclado y ambiguo. Por esta razón el futuro estaba reservado para ellas; eran los sustitutos naturales y necesarios de otros tipos de castigo que estaban desapareciendo. Pero, por otro lado, ellos mismo sufrieron la ley del debilitamiento de intensidad. Es por eso que mientras originalmente estaban mezclados con penalidades adicionales de las que a veces no eran más que subsidiarios, poco a poco se desprendieron de ellas hasta dejarlas reducidas a la forma más simple, es decir la privación de la libertad sin comprender otras gradaciones que las que resultan de las diferencias en la duración de esta privación.

De este modo, las variaciones cualitativas en el castigo dependen en parte de los cambios cuantitativos que han sufrido al mismo tiempo. En otras palabras, de las dos leyes que hemos establecido, la primera contribuye a la explicación de la segunda. El tiempo llega, a su vez, para explicarla. 


\section{EXPLICACIÓN DE LA PRIMERA LEY}

Para facilitar esta explicación, consideraremos aisladamente los dos factores que hemos distinguido, y como el segundo es el que juega el rol menos importante, empezaremos haciendo abstracción de él. Busquemos entonces cómo se suavizan las penas a medida que se pasa de sociedades inferiores a sociedades más elevadas, sin ocuparnos provisoriamente de las perturbaciones que puedan deberse al carácter más o menos absoluto del poder gubernamental.

Se puede estar tentado de explicar el suavizamiento por el suavizamiento paralelo de las costumbres. Tenemos cada vez más horror a la violencia, las penas violentas, es decir crueles, deben entonces inspirarnos una repugnancia creciente. Desgraciadamente la explicación se vuelve contra sí misma. Si por una parte nuestra gran humanidad nos aparta de los castigos dolorosos, ella nos hace parecer más odiosos los actos inhumanos que esos castigos reprimen. Si nuestro altruismo más desarrollado repugna la idea de hacer sufrir al prójimo, por la misma razón, los crímenes que son contrarios a estos sentimientos deben parecernos más abominables y por lo tanto, tendemos a reprimirlos más severamente. Esta tendencia no puede ser neutralizada más que parcialmente y débilmente por la tendencia opuesta, del mismo origen, que nos lleva a hacer sufrir al culpable lo menos posible. Es evidente que nuestra simpatía debe estar menos con él que con la víctima. Entonces, la delicadeza de las costumbres debiera traducirse en un endurecimiento penal, al menos para los crímenes que lesionan a terceros. De hecho, cuando comienza a aparecer de manera marcada en la historia, es así que se manifiesta. En las sociedades inferiores, los homicidios, los robos simples no eran castigados más que ligeramente, porque las costumbres al respecto son groseras. En Roma, durante mucho tiempo, la violencia no fue considerada más que como vicio de los contratos, lejos de tener carácter penal. Es a partir del día en que se afirmaron y desarrollaron los sentimientos de simpatía del hombre por el hombre que esos crímenes fueron castigados más duramente. El movimiento hubiera debido continuar, si otra causa no hubiera intervenido.

Puesto que la pena depende del crimen y expresa la manera en la que afecta la conciencia pública, es en la evolución del crimen que debemos buscar la causa que determinó la evolución de la pena.

Sin que sea necesario entrar en el detalle de las pruebas que justifican esta distinción, se acordará con nosotros sin esfuerzo, creemos, que todos los actos reputados criminales por las diferentes sociedades conocidas pueden repartirse en dos categorías fundamentales: unos dirigidos contra cosas colectivas (materiales o ideales, no importa) de las cuales las principales son la autoridad pública y sus representantes, las costumbres y las tradiciones, la religión; otros sólo ofenden individuos (muertes, robos, violencias y fraudes de todo tipo). Las dos formas de criminalidad son bien distintas y corresponde darles nombres diferentes. La primera podría ser llamada criminalidad religiosa, porque los atentados contra la religión son la parte más esencial y porque los crímenes contra las tradiciones y los jefes de estado tienen siempre, más o menos, carácter religioso; a la segunda, se le podría reservar el nombre de criminalidad humana. Establecido esto, se sabe que los crímenes de la primera especie llenan, casi con exclusión de todos los otros, el derecho penal de las sociedades inferiores; pero que disminuyen, al contrario, a medida que se avanza en la evolución, mientras que los atentados contra la persona humana toman cada vez más todo el espacio. Para los pueblos primitivos, el crimen consistía casi únicamente en no cumplir los ritos de culto, en violar las prohibiciones rituales, en separarse de las costumbres de los mayores, en desobedecer la autoridad, allí donde estaba fuertemente constituida. Al contrario, para el europeo de hoy, el crimen consiste esencialmente en la lesión de cualquier interés humano.

Entonces, estas dos formas de criminalidad difieren profundamente porque los sentimientos colectivos que ofenden no son de la misma naturaleza. De ello resulta que la represión no 
puede ser la misma para una u otra.

Los sentimientos colectivos que transgrede y ofende la criminalidad específica de las sociedades menos desarrolladas son colectivos de dos modos: no solamente tienen por sujeto la colectividad y en consecuencia existen en la conciencia de la mayor parte de los individuos, sino que también tienem por objeto cosas colectivas. Por definición estas cosas están fuera del campo de nuestros intereses privados. Los fines a los que estamos así vinculados sobrepasan infinitamente el limitado horizonte que cada uno de nosotros posee. No nos conciernen personalmente sino que conciernen a la entidad colectiva. Consecuentemente, los actos que estamos obligados a realizar para alcanzarlos, no derivan de las inclinaciones de nuestra naturaleza individual, sino que más bien tienden a violarla, ya que consisten en toda una variedad de sacrificios y privaciones que el hombre se impone a sí mismo para agradar a Dios o para satisfacer la costumbre o para obedecer la autoridad. No tenemos inclinaciones a ayunar, a mortificarnos, a abstenernos de esta o aquella comida, a sacrificar a nuestros animales favoritos en el altar, a sufrir incomodidad con respecto a las costumbres, etc. Así, del mismo modo que las sensaciones que vienen del mundo externo, tales sentimientos están en nosotros pero no son nuestros; es más, en cierta medida están allí a pesar de nosotros y tienen este carácter por la coacción que ejercen sobre nosotros.

Por eso estamos obligados a alienarlos, a relacionarlos con alguna causa externa, como hacemos con las sensaciones. Por otra parte estamos obligados a concebirlos como un poder que no sólo está separado de nosotros sino que es superior a nosotros, ya que nos manda y le obedecemos. Esta voz que nos habla de un modo imperativo que nos lleva a cambiar nuestra propia naturaleza, sólo puede provenir de un ser que sea distinto de nosotros y que también nos domine. De cualquier modo específico que los hayamos retratado, Dios, ancestros, personalidades augustas de todo tipo, siempre posee en relación con ellos una cualidad trascendente o superhumana. Es por eso que este aspecto de la moralidad está penetrado por la religiosidad; es por eso que las obligaciones que debemos cumplir nos llevan a obedecer a una personalidad que es infinitamente superior a la nuestra. Esta es la personalidad colectiva tal como la concebimos en una forma puramente abstracta o, como es el caso más común, con la ayuda de símbolos enteramente religiosos.

Pero entonces, los crímenes que violan estos sentimientos y que consisten en la omisión de llevar a cabo obligaciones específicas no pueden sino aparecérsenos como dirigidos directamente contra los seres trascendentes, ya que, en realidad, se relacionan con ellos. De esto se sigue que nos parecen excepcionalmente ofensivos porque una transgresión es mucho más ofensiva si el ofendido es superior en naturaleza y dignidad al transgresor. Cuanto más respeto se tiene a algo, más horrible es una falta de respeto. El mismo acto que, dirigido contra un igual es meramente reprensible, se vuelve impío cuando concierne a un ser superior a nosotros: el horror que inspira solamente puede ser atemperado con la represión violenta. Los fieles normalmente deben someterse a múltiples privaciones para complacer a sus dioses y mantenerse en contacto regular con ellos. ¿A qué privaciones entonces tendrían que someterse cuando los han afrentado?. Aun cuando haya fuertes sentimientos de piedad hacia el culpable, ese sentimiento no contrabalancea la indignación levantada por el acto de sacrilegio.

Consecuentemente tampoco modifica perceptiblemente el castigo, porque los dos sentimientos son demasiado desiguales. La simpatía que puede sentir un hombre por uno de sus semejantes, particularmente degradado por una falta, no puede revertir el temor reverencial que se siente por la divinidad. Comparado con este poder, que lo supera tanto, el individuo parece tan pequeño que sus sufrimientos pierden su significado relativo y se vuelven una cantidad despreciable. ¿Cuál es la importancia del sufrimiento individual cuando hay un Dios que debe ser apaciguado?

Diferente es el caso con los sentimientos colectivos cuyo objeto es el individuo, porque cada uno de nosotros es uno de ellos. Lo que le 
concierne al hombre nos concierne a todos, porque todos somos hombres.

Esos sentimientos vinculados con la protección de la dignidad humana nos tocan personalmente. Por supuesto, no quiero decir que respetemos la vida y la propiedad de nuestros semejantes solamente con motivo de cálculos utilitarios, para obtener un intercambio limpio de ellos. Si condenamos los actos que los atacan es porque transgreden sentimientos de simpatía que sostenemos por el hombre en general, y estos sentimientos son desinteresados, porque tienen un objeto general. Esta es la gran diferencia que separa el individualismo moral de Kant de los utilitaristas.

Ambos hacen del desarrollo del individuo, en cierto sentido, el objeto de la conducta moral, pero, para los últimos, el "individuo" del que se trata es el individuo sensible, empírico, tal como puede ser captado en cada mente especifica. Para Kant, por su parte, es el ser humano, la humanidad en general, en abstracción de las diversas formas concretas en que se manifiesta. Sin embargo, tan universal como pueda ser, un objetivo de esas características está directamente vinculado con aquello que mueve nuestras inclinaciones egoístas. Entre el hombre en general y el hombre que es cada uno de nosotros, no existe la misma diferencia que la que se da entre un hombre y un dios. El carácter de este ideal solamente difiere de nuestro propio ideal en grado: es simplemente el modelo del que cada uno de nosotros es una instancia diferente. Los sentimientos por los que nos encontramos vinculados son así, en parte, solamente una extensión de aquellos que nos unen con nosotros mismos. Esto se halla expresado en el dicho popular "No hagas a los otros lo que no quisieras que te hagan a ti mismo".

En consecuencia, para explicarnos estos sentimientos y los actos que nos incitan, no es necesario, al mismo grado, buscarles un origen trascendente. Para darnos cuenta del respeto que nos inspira la humanidad no necesitamos imaginar que nos lo impone un poder exterior y superior a la humanidad; nos parece inteligible por lo que sentimos como hombres nosotros mismos. No veremos en ellos actos de lesa divinidad, sino de lesa humanidad. Sin dudas, es preciso que ese ideal esté despojado de toda trascendencia; está en la naturaleza de todo ideal sobrepasar lo real y dominarlo. Pero esa trascendencia es mucho menos marcada. Si este hombre abstracto no se confunde con alguno de nosotros, cada uno de nosotros lo realiza en parte. Por elevado que sea el fin, como es, esencialmente humano, nos es también, en alguna medida, inmanente.

Por ende, las condiciones de la represión no son las mismas que en el primer caso. Ya no hay distancia entre ofensor y ofendido, están ambos en el llano. Más aún cuando, en cada caso particular, la persona humana a la que el crimen ofende se presenta con una individualidad particular, idéntica en todo aspecto a la del culpable. El escándalo moral, que constituye el acto criminal, tiene algo de menos revulsivo, y por lo tanto no reclama una represión tan violenta. El atentado de un hombre contra un hombre no puede levantar tanta indignación como el atentado de un hombre contra un dios. Al mismo tiempo, los sentimientos de piedad que nos inspira el que sufre la pena no pueden ser tan fácil ni completamente ahogados por los sentimientos que ha ofendido y que reaccionan contra él; unos y otros son de la misma naturaleza. Los primeros sólo son una variedad de los segundos. Lo que atempera la cólera colectiva que es el alma de la pena es la simpatía que sentimos por todo hombre que sufre, el horror que nos causa toda violencia destructiva; ahora bien, es la misma simpatía y el mismo horror que alumbró la misma cólera. Así, esta vez, la causa misma que pone en marcha al aparato represivo tiende a detenerlo. El mismo estado mental nos impulsa a castigar y a moderar la pena. No podía faltar una influencia atenuante. Podía parecer bien natural inmolar sin reserva la dignidad humana del culpable a la majestad divina ofendida. Por el contrario, hay una verdadera e irremediable contradicción en vengar la dignidad humana ofendida en la persona de la víctima, violándola en la persona del culpable. El solo medio, no de levantar la antinomia (que en rigor no es solucionable) 
pero de reducirla, es reducir la pena tanto como sea posible.

En consecuencia, si, tal como hemos explicado el crimen se reduce progresivamente a las ofensas contra las personas solamente, mientras que las formas religiosas de criminalidad declinan, resulta inevitable que la fuerza promedio del castigo se vuelva más débil. Este debilitamiento no surge del hecho de que las costumbres se vuelvan menos severas sino del hecho de que la religiosidad, de la que estaban originalmente tomados, y el derecho penal y los sentimientos colectivos que eran su base, disminuyen. Sin duda, los sentimientos de simpatía humana se vuelven, a la vez, más fuertes. Pero su creciente fuerza no puede explicar esta reducción progresiva en el castigo, ya que, por si mismo, esto tenderá más bien a volvernos más severos frente a cada crimen en el que la víctima sea un hombre y de ese modo, incrementará el castigo por tales crímenes. La verdadera razón es que la compasión que se siente por el hombre condenado ya no se ve obviada por sentimientos opuestos que no permiten que se la sienta.

Pero, nos dirán, si es así, ¿cómo resulta que las penas de los atentados contra las personas participan de la regresión general? Ya que, si bien han perdido menos que las otras, lo cierto es que también son menos elevadas que hace dos o tres siglos. Si, sin embargo, está en la naturaleza de esta clase de crímenes llamar a castigos menos severos, el efecto hubiera debido manifestarse de inmediato, cuando el carácter criminal de esos actos fue reconocido formalmente; las penas que les corresponden hubieran debido alcanzar de golpe el grado de suavidad que hoy tienen, en lugar de reducirse progresivamente. Pero lo que determina la suavización progresiva es que al momento en que esos atentados, después de haber permanecido largo tiempo en el umbral del derecho penal, lo penetraron y fueron definitivamente clasificados, era la criminalidad religiosa la que ocupaba casi todo el espacio. Como resultado de esa situación preponderante, ella comenzó a arrastrar en su órbita a los delitos nuevos que acababan de constituirse, y los marcó con su huella. Así, de un modo general, el crimen era concebido como una ofensa dirigida a la divinidad, y por ello los crímenes de los hombres contra los hombres fueron concebidos sobre el mismo modelo. Creíamos que nos repugnaban porque están prohibidos por los dioses, y a ese título, los ofenden. Los hábitos del espíritu son tales que no parece posible que un mismo precepto moral pueda tener una autoridad suficientemente fundada si no la toma prestada de lo que era entonces considerado fuente única de la moralidad. Tal es el origen de esas teorías, tan extendidas aún hoy, de acuerdo con las cuales la moral carece de toda base si no se apoya sobre una religión, o cuando menos, sobre una teología racional, es decir si el imperativo categórico no emana de algún ser trascendente. Pero a medida que la criminalidad humana se desarrolla y la criminalidad divina retrocede, la primera desprende cada vez con mayor nitidez su fisonomía propia y sus caracteres distintivos, como los hemos descripto. Se libera de las influencias que sufría y que le impedían se ellas mismas. Si aún hoy, hay buena parte de espíritus que creen que el derecho penal y, en general, toda moral, son inseparables de la idea de Dios, su número poco a poco disminuye y aquellos que se demoran en la concepción arcaica no unen ambas ideas más de lo que lo haría un cristiano de los primeros tiempos. La moral humana se despoja cada vez más de su carácter confesional. En el curso de este desarrollo se produce la evolución regresiva de las penas que castigan las faltas más graves a las prescripciones de esta moral.

Por un retorno que debe señalarse, a medida que la criminalidad humana gana terreno, a su turno reacciona a la criminalidad religiosa y, por decirlo de algún modo, se le asimila. Si hoy son los atentados contra las personas los que constituyen los principales crímenes, existen sin embargo atentados contra cosas colectivas, crímenes contra la familia, el estado o las costumbres. Sólo que estas cosas colectivas tienden a perder, ellas mismas, el carácter religioso que antes las marcaba. De ser divinas, se convirtieron en realidades humanas. No ubicamos a la familia o a la sociedad como entidades místicas y 
trascendentes, sino que vemos en ellas sólo grupos de hombres que conciertan sus esfuerzos para realizar los fines humanos. Resulta entonces que los crímenes dirigidos contra esas colectividades participan de los caracteres de aquellos que lesionan directamente los individuos, y las penas que castigan los primeros se suavizan.

Tal es la causa del debilitamiento progresivo de las penas. Se ve que este resultado se produce mecánicamente. La manera en la que los sentimientos colectivos reaccionan contra el crimen ha cambiado, porque esos sentimientos han cambiado. Fuerzas nuevas han entrado en juego. El efecto no podía seguir siendo el mismo. Esta gran transformación no ocurrió a la vista de un fin preconcebido ni bajo el imperio de concepciones utilitarias. Pero, una vez cumplida, se encontró naturalmente ajustada a fines útiles. Por lo mismo que era necesariamente el resultado de condiciones nuevas en las que se encontraron ubicadas las sociedades, no podía no ajustarse en armonía con aquellas condiciones. En efecto, la intensidad de las penas sólo sirve para hacer sentir a las conciencias particulares la energía del mandato social; sólo es útil si varía con la intensidad de ese mandato. Conviene entonces que se modere a medida que la coerción colectiva se aliviana, se flexibiliza, deviene menos excluyente del libre examen. Así está ahí el gran cambio que se produjo a lo largo de la evolución moral. Siempre que la disciplina social, cuya moral propiamente dicha es su expresión más elevada, extiende cada vez más su campo de acción, pierde cada vez más su rigor autoritario. Porque toma algo más humano, deja más espacio a las espontaneidades individuales, las solicita incluso. Tiene menos necesidad, pues, de ser violentamente impuesta. Así también es necesario que las sanciones que aseguran su respeto devengan menos compresivas de toda iniciativa y de toda reflexión.

Podemos ahora volver al segundo factor de la evolución penal, del que hasta ahora hicimos abstracción, es decir la naturaleza del órgano gubernamental. Las consideraciones precedentes permiten explicar fácilmente la manera en que se comporta.
En efecto, la constitución del poder absoluto necesariamente tiene como resultado elevar a quien lo detenta por encima del resto de la humanidad, de convertirlo en algo sobrehumano y esto en mayor medida cuanto más ilimitado es el poder. De hecho, en cualquier parte en que el gobierno toma esa forma, el que lo ejerce aparece ante los hombres como una divinidad. Cuando no se lo convierte en un dios especial, se ve cuando menos que el poder del que está investido es una emanación del poder divino. Entonces esa religiosidad no puede sino surtir sus efectos ordinarios sobre la pena. Por una parte, los atentados dirigidos contra un ser tan sensiblemente superior a todos los ofensores no serán considerados crímenes ordinarios, sino sacrilegios, y a ese título, reprimidos violentamente. De allí se deriva que en todos los pueblos sometidos a un gobierno absoluto los crímenes de lesa majestad tengan un rango excepcional. Por otra parte, en esas mismas sociedades, casi todas las leyes son consideradas como emanadas del soberano y de su voluntad, y es por tanto contra él que parecen dirigirse las principales violaciones de la ley. La reprobación que esos actos levantan es mucho más viva que si la autoridad que ofendiesen estuviera mejor repartida, más moderada. El hecho de que esté en este punto concentrada, lo que la hace más intensa, la convierte en más sensible a las ofensas y más violenta en sus reacciones. Es así que la gravedad de casi todos los crímenes se encuentra aumentada en algunos grados, por lo tanto la intensidad promedio de las penas es extraordinariamente reforzada.

\section{CONCLUSIONES}

Así entendida, la ley que acabamos de analizar tiene una significación diferente. Si se va al fondo de la cuestión, podemos ver ahora que ella no expresa solamente -como parecía al principio-las variaciones cuantitativas por las que transcurrió la pena, sino variaciones propiamente cualitativas. Si la pena es más suave hoy que antaño, no es porque las ancianas instituciones 
penitenciarias, manteniéndose ellas mismas, hayan perdido en parte su rigor; sino porque fueron reemplazadas por instituciones diferentes. Los móviles que han determinado la formación de unas y otras no son de igual naturaleza. No es la vivacidad, la explosión repentina, la estupefacción indignada que levanta una ofensa dirigida contra un ser cuyo valor es inconmensurable respecto del agresor; es más bien la emoción más calma y reflexiva que provocan las ofensas que ocurren entre iguales. El reproche no es el mismo, y no excluye la conmiseración; por sí mismo, llama a atemperarse. De allí la necesidad de nuevas penas que acuerden con esta nueva mentalidad.

Así podemos apartar un error al que podría llevarnos la observación directa de los hechos. Viendo con qué regularidad la represión parece moderarse a medida que se avanza en la evolución, se podría creer que el movimiento está destinado a continuar sin interrupción. Dicho de otro modo, que la pena tiende a convertirse en cero. Una consecuencia tal estaría en contradicción con el verdadero sentido de nuestra ley.

La causa que ha producido esta regresión no podría producir sus efectos atenuantes indefinidamente. Porque ella no consiste en un aletargamiento de la conciencia moral que, perdiendo poco a poco su vitalidad y sensibilidad originales, se torna incapaz de toda reacción penal enérgica. No somos hoy más complacientes que antaño para todos los crímenes indistintamente, sino sólo respecto de algunos, y con otros nos mostramos más severos. Sólo que aquellos por los que testimoniamos una indulgencia creciente, son los que tenían represión más violenta; inversamente, a los que reservamos nuestra severidad son los que reclamaban una pena más moderada. En consecuencia, a medida que los primeros cesan de ser tratados como crímenes y se retiran del derecho penal, cediendo su lugar a los otros, debe necesariamente producirse un debilitamiento promedio de las penas. Pero este debilitamiento no puede durar más de lo que durará esa sustitución. Llegará un momento -casi ha llegadoen que la sustitución estará completa, los atenta- dos contra las personas llenarán todo el derecho criminal, o lo que quede de los otros crímenes será considerado dependiente de aquellos. Entonces, el retroceso se detendrá. No hay razón para creer que la criminalidad humana deba retroceder a su turno como las penas que la reprimen. Todo hace prever que se desarrollará más y más, que la lista de actos considerados delitos crecerá, y su carácter criminal se acentuará. Los fraudes, las injusticias, que ayer dejaban la conciencia pública casi indiferente, la revuelven hoy día y esta sensibilidad se acentuará con el tiempo. No hay en realidad un aflojamiento general del sistema represivo, sólo un sistema particular se flexibiliza, pero es reemplazado por otro que aunque menos violento y menos duro, no deja de tener sus severidades propias y no está destinado a una decadencia ininterrumpida.

Así se explica la crisis del sistema penal en los pueblos civilizados. Hemos llegado al momento en que las instituciones penales del pasado han desaparecido o no sobreviven más que por la fuerza de la costumbre, sin que nazcan otras que respondan mejor a las aspiraciones nuevas de la conciencia moral.

(Recebido para publicação em dezembro de 2008) (Aceito em março de 2009) 


\section{TWO LAWS OF THE PENAL EVOLUTION}

\section{Emile Durkheim}

This text discusses the changes of punishment throughout history of the societies. It analyzes the softening of physical punishment and the ascension of prison as main locus of punishment in the modern world. It relates these processes with the social differentiation, character of power and change in the conception of crimes. It points the need for the creation of penal institutions that answer better to the new aspirations of moral conscience.

KEYWORDS: penal evolution, physical punishment, prison, moral conscience.

\section{DEUX LOIS DE L'EVOLUTION PENALE}

\section{Emile Durkheim}

Ce texte parle des changements de punition tout au long de l'histoire des sociétés. On y analyse l'allègement des châtiments physiques et l'avènement de la prison comme lieu central de punition dans le monde moderne. Ces processus sont mis en relation avec la différenciation sociale, le type de pouvoir et le changement de conception concernant les délits. Le besoin de créer des institutions pénales capables de mieux répondre aux nouvelles aspirations de la conscience morale y est mis en évidence.

MoTs-CLÉS: évolution pénale, châtiment physique, prison, conscience morale. 